\title{
Survey Uses May Influence Survey Responses
}

A PREPRinT

\author{
Melissa G. Wolf |" \\ University of California, Santa Barbara \\ Delfi Diagnostics \\ https://orcid.org/0000-0001-7677-0659 \\ missgord@gmail.com
}

\author{
Alexander J. Denison \\ Clemson University
}

https://orcid.org/0000-0002-4291-8325

alexjdenison@gmail.com

February 26, 2023

\begin{abstract}
When validating psychological surveys, researchers tend to concentrate on analyzing item responses instead of the processes that participants use to generate these responses. When screening for invalid responses, researchers have generally focused on participants who manipulate their answers for personal gain or respond carelessly. In this paper, we introduce a new invalid response process, discordant responding, that arises when participants disagree with the use of the survey and discuss similarities and differences between this response style and protective responding. Results show that nearly all participants reflect on the intended uses of an assessment when responding to items and most decline to respond or modify their responses if they are not comfortable with the way the results will be used. Incidentally, we also find that participants may misread survey instructions if they are not interactive. We introduce a short screener to detect invalid responses with dishonest responder identifiers (DRI), providing researchers with more confidence in the validity of their inferences. Finally, we provide recommendations about how researchers may use these findings to design surveys that reduce this response manipulation in the first place.
\end{abstract}

Keywords Survey $\cdot$ Validity $\cdot$ Honesty $\cdot$ Invalid Response $\cdot$ Assessmenet $\cdot$ Attention $\cdot$ Participant Motivation

\section{Introduction}

Self-report surveys are commonly used to measure psychological properties and form the basis of much of psychological research. Psychological measurement is inherently more complex than physical measurement because psychologists must contend with the interaction between subjects and the instrument in addition to normal sources of measurement error. For example, when measuring the length of an object a physical scientist may use a defective yardstick and consistently under-report the length of an object (systematic error) or they may use a perfect yardstick and occasionally hold it incorrectly (random error). However, there is no concern that the object itself may intentionally manipulate the yardstick to misrepresent its length (unless, of course, the object is a human). Because humans can intentionally manipulate the psychological scales used to assess them, social science must worry about a third type of error, which is error due to invalid responses.

We define invalid responses as a mismeasurement resulting from the interaction between the participant and the survey instrument. Such responses are a threat to validity, defined by Borsboom, Mellenbergh, and van Heerden (2004) as the causal relationship between variation on the attribute and variation on the outcome (AERA, APA, NCME, 2014), because the process driving responses is unrelated (or only somewhat related) to the attribute being assessed. This type of error is neither random, as there are consistent features that may elicit this behavior, nor systematic, as it is not a stable issue with the instrument or environment, but the interaction between a specific context and individual. This may make certain scales valid for individuals

\footnotetext{
${ }^{*}$ The authors thank Michael J. Furlong for his thoughtful feedback and motivation to pursue this area of research.
} 
in one context, but invalid in a different context. For example, a participant may respond differently if the survey is anonymous or non-anonymous and this propensity may also differ across individuals, meaning the assessment results may be valid for certain individuals in one context but not others. As such, we take the stance that validity is not a stable property of a survey but rather refers to the adequacy of the survey results for a particular use or purpose (Kane, 2013; Messick, 1995).

Invalid responses on psychological assessments are generally grouped into two categories, content responsive and content non-responsive. Content-responsiveness refers to the degree that participants modify their response based on the content of the survey, while content non-responsiveness refers to participants that give invalid responses without any regard for what the survey questions ask. Within these broad categories individuals may have different motivations and response processes, which yield different response patterns in the data. All invalid responding can be conceptualized as an individual difference, context specific state, or an interaction between the two. Below we provide a summary of commonly studied invalid response constructs.

\subsection{Content Non-responsive Invalid Responding}

Content non-responsive behavior involves invalid responding where the participant does not pay attention to the items or content of the survey they are responding to, leading to responses that have no relation to the content of the survey itself. This type of behavior is typically referred to as careless or insufficient effort responding, but has also been called random responding or response inconsistency (Baer et al., 1997; Bagby \& Sellbom, 2018). Careless responding has a long history of study in the areas of clinical, personality, industrial organizational, and educational psychology. Initial systemic work on this phenomenon can be traced to the Minnesota Multiphasic Personality Inventory-2 (MMPI-2) and the development of the Variable Response Inconsistency (VRIN) and True Response Inconsistency (TRIN) subscales (Baer et al., 1997; Berry et al., 1992; Nichols et al., 1989). As the names of these subscales suggest, the initial study of careless responding focused on overly inconsistent (or random) response patterns (Berry et al., 1992; Nichols et al., 1989), however recent work also includes overly consistent response patterns (such as long strings of identical responses; Johnson, 2005). It is now accepted that careless respondents can engage in either of these response patterns when responding carelessly (Curran, 2016).

Content non-responsive behavior is thought to be caused by a lack of motivation by the participant or because the survey is perceived as unimportant. While a honest and thoughtful respondent has the goal of selecting the response options that best characterize them, a careless respondents goal is to complete the survey as fast or with as little effort as possible (Curran, 2016). The literature examining how individual differences relate to careless responding is still developing, but one consistent finding is that individuals low in conscientiousness and agreeableness tend to be more careless (Berry et al., 2019; Bowling et al., 2016; Maniaci \& Rogge, 2014; Nichols \& Edlund, 2020). There is also work examining situational factors that influence careless responding, with two main factors being that longer, low stakes surveys tend to produce more carelessness (Bowling et al., 2020; Brower, 2018; Meade \& Craig, 2012). Thus, researchers may attempt to reduce careless responding my shortening the survey, raising the stakes (e.g., by warning participants that the researchers will know if they are careless), or by increasing participant motivation (e.g., offering some benefit for responding conscientiously).

Beyond the MMPI-2, several methods have been developed to detect careless responses, including inconsistency indices (Ben-Porath, 2011), attention check or infrequency items (Curran \& Hauser, 2019; Kung et al., 2018), statistical techniques that identify unlikely response patterns (Curran, 2016), self-reported careless responding or diligence, and unlikely completion times (Meade \& Craig, 2012). These methods capitalize on the fact that careless respondents will produce different patterns of data than conscientious respondents do because they rush through the survey and do not pay attention to the content of the items they respond to. As mentioned above, these patterns are overly inconsistent behavior (often called random responding) where participants have highly inflated response variance, and overly consistent responding, where participants may select the same option for every response or select a pattern of responses with low variance (e.g., 1, 2, 1, 2...). Thus, there are several known and observable response patterns indicative of this type of invalid response, making it easier for these observations to be removed from a dataset.

\subsection{Content Responsive Invalid Responding}

Contrasting the above behavior is invalid responding that is content-responsive. Where content-nonresponsive behavior ignores item content, content-responsive behavior involves participants manipulating their responses to a survey based on the content of items in order to achieve a desired outcome. This behavior could be thought of similarly to cheating on a test, but instead of artificially inflating their test scores, individuals 
either artificially inflate or deflate their scores on a non-ability construct by overreporting or underreporting behavior. This behavior is easier to execute than cheating because non-ability constructs do not have an objectively correct or incorrect answer. Where a cheater must have some outside aid that helps them select the correct answer, content-responsive invalid respondents only need to understand the question well enough to manipulate it in the desired direction. This behavior also has a long history of study in psychology, which similar to careless responding, saw initial systematic development with the MMPI (Nederhof, 1985). Content-responsive invalid responding predates content non-responsive invalid responding and emerged around the development of the original MMPI (Meehl \& Hathaway, 1946).

Content responsive invalid responding is often categorized as "faking good" or "faking bad" (Grow et al., 1980). Faking good, also called social desirability bias (Krumpal, 2013), positive impression management, or underreporting (McGrath et al., 2010), involves the participant manipulating their responses to present an overly positive or desirable image of themselves (e.g., to appear as a better candidate for a job). Faking bad, also called mischievous responding (Robinson-Cimpian, 2014), malingering, feigning (Rogers et al., 2003), negative impression management (Krohn et al., 2013), or overreporting (McGrath et al., 2010) involves the participant presenting an overly negative image of themselves (e.g., to obtain a mental health diagnosis). Respondents may also engage in "expressive responding" in which they intentionally give responses that show support for their in-group or hostility to their out-group (e.g., Trump voters may disingenuously report believing in the Pizzagate conspiracy to express solidarity with Republicans and dissention from Democrats; Ross \& Levy, 2023).

The specific goal and motivation for this type of response behavior depends on both individual differences and the specific context that an assessment is given. While the behaviors above often involve the goal of self-presentation, participants may have other goals as well. For example, Cimpian and Timmer (2019) found that adolescents may intentionally misidentify as LGBTQ on surveys (especially when completing a survey at school rather than at home; Fish \& Russell, 2018) and then select other responses that they find "humorous", e.g., suicidal ideation, drug use, and gang involvement, which can skew inferences about the youth LGBTQ community. In this paper we focus on a motivation related to faking "good"; specifically, response manipulation out of concern or fear about how the results might be used, e.g., intentionally giving uninteresting, average responses to avoid unwanted recognition (Tourangeau \& Yan, 2007). As such, this phenomenon could also be described as "faking normal", which may be more difficult to identify than faking good or bad as the resulting response patterns would be characteristic of a "normal" response.

Because of the wide variety of goals a participant may have for manipulating their responses, the specific detection or prevention strategy may vary or may be ignored entirely in favor of focusing on suspicious patterns of responding in the raw data. For example, if a researcher believes participants are faking by reporting extreme symptoms to receive a psychiatric diagnosis, they may use a screener focused solely on that response behavior, such as an extreme response screener, to remove participants who report an improbably high combination of low-frequency attributes, (Cimpian et al., 2018). The MMPI-2 has many subscales that are designed to detect these behaviors in order to screen for suspicious patterns of responding (Graham, 2006). Similar to content non-responsive behavior, areas outside of clinical psychology have also developed their own methods for detecting or deterring this behavior, with perhaps the most well-known being social desirably scales, which detect respondents who present an overly positive image of themselves. For example, the item "I sometimes litter", has a culturally "correct" answer of "no". Participants who answer the majority of these items in a socially desirable manner are flagged as potentially manipulating their responses (Crowne \& Marlowe, 1960; Stöber, 2001).

Recent work has also examined methods to prevent faking altogether. The most common environmental factor that induces faking is high stakes assessment. As discussed above, the primary goal of faking is to achieve some outcome (e.g., employment, or a diagnosis), so it is unsurprising that high stakes assessment is related to faking. If the assessment was low stakes the participant would have less to gain from faking, so it is less likely to occur. However, unlike careless responding, it is often difficult to alter the stakes of the assessment to reduce faking. Let us again use the example of an employee who fakes on a job application. How does one lower the stakes on a job application? Short of lying to the participant about the use of the survey, this is difficult to achieve. Similarly, warnings not to fake may be less effective if participants do not believe it is reasonable that they could be detected and could simply lead them to fake more carefully to avoid detection, similar to how warning a student not to cheat may simply cause them to cheat more carefully. These difficulties are why behavior-focused screening, such as the methods discussed above, is generally a more popular approach when dealing with content-responsive invalid responding. 
One relatively new method of preventing faking that shows promise is the use of forced choice questions instead of traditional Likert-surveys. As a simple example of a forced choice item, a participant may be presented with two options measuring different constructs and asked to pick the one that fits them best. These items are designed to be equally socially desirable, which makes it more difficult for the respondent to manipulate their score. For example, someone applying for a sales position may be asked to pick the statement that best describes them from the following choices: "I am a very persuasive person" and "I am attentive to details and make few mistakes". Both qualities are desirable for a sales position, so the applicant may find it harder to manipulate their scores to be the most desirable candidate. A downside of this approach is that researchers must establish item pairs that are equally socially desirable before a survey can be used, which is often more labor intensive than constructing a traditional survey. Scoring of the results is also more complex than traditional assessments, where responses can often be easily summed to create a total score (Cao \& Drasgow, 2019).

Finally, there has also been extensive work on methods to reduce dishonest responding to sensitive survey items, which we call protective responding as the participants goal is generally to protect themselves or their image (similar to social desirability bias; Fowler, 1995). These methods either modify the item itself or the way the item is asked to decrease perceptions of sensitivity or increase the participants motivation to respond honestly (Tourangeau \& Yan, 2007). For example, one technique is to use indirect questioning methods instead of traditional Likert or yes/no surveys. One such method is the list experiment, which involves giving a list of items to an experimental and control group and asking them the total number of items they agree with. These lists are identical across experimental and control groups except for one sensitive item, which is only shown to the experimental group. Researchers can then compare the summed agreement between treatment and control groups to determine endorsement of this sensitive item. This method reduces dishonesty about these topics because participants believe there is no way for researchers to know if they have endorsed the sensitive item or the other non-sensitive items because they simply report the total number of items agreed with (excluding the scenario where all items are endorsed; Rosenfeld et al., 2016). Another common method to reduce this behavior is by making surveys anonymous when possible (Tourangeau \& Smith, 1996).

\subsection{Current Study}

In the current study we discuss a new motivation for responding dishonestly: participants who manipulate their responses because of how they believe the survey results will be used. The motivation for this response style overlaps with protective responding but is broader in scope. Where protective responding can be considered an item-level phenomenon this response style is a survey-level phenomenon as participants disagree with or distrust the assessment or assessment-givers themselves, which may encourage them to "fake normal" to avoid unwanted attention. For example, an individual may deny being disabled on a job application even though discriminatory hiring practices based on disability status are prohibited by law in the United States because they do not trust that their response will not be used against them. As Tourangeau and Yan (2007) state, when taking a survey it is not unreasonable to expect that respondents may "lie for pretty much the same reasons they lie in everyday life", which may include lying due to disagreement with the use of the assessment itself. To reflect that the motivation for this response manipulation is disagreement we call this response style discordant responding. We assert that discordant responding is primarily an interaction between an individual and the survey context and not a stable individual difference or contextual factor ${ }^{2}$ Further, we suggest that discordant responding is malleable and can be minimized by researchers who employ conscientious survey design to boost trust with participants.

In this paper, we begin by establishing that discordant responding occurs by showing participants (1) think about how surveys will be used, and (2) that perceived use can influence how they respond to survey items. After demonstrating that this type of invalid responding poses a threat to the validity of inferences, we investigate motivations for giving discordant responses. Next, we develop a simple method to detect dishonest responses and investigate approaches that may be taken to help mitigate discordant responses. Finally, we present several incidental findings about survey development that can be used to motivate participants to pay closer attention or increase participant buy-in.

Through this work we highlight the importance of participant motivation in educational and psychological assessment and hope to expand discussion in this area to include factors such as these, which may bias assessment results. Our findings are especially important given the results of Clairmont, Wolf and Maul

\footnotetext{
${ }^{2}$ Although we believe that that discordant responding is generally a malleable context-specific state, it may also be related to individual differences like general dishonesty and contextual factors like survey anonymity.
} 
(2018), who found that young people reported being dishonest on surveys to protect themselves primarily due to distrust in the organization administering the survey and/or perceived negative outcomes from the use of the results. Honest responses by these individuals are especially important for potentially sensitive topics, such as mental health and substance abuse, as early intervention in these areas is critical (Splett et al., 2013). Because of this, we concentrate on discordant responses young adults give to school surveys and hypothesize that perceived assessment use is inextricable from psychological measurement and validation of participants' responses processes.

\section{Method}

To explore discordant responding we collected data in three separate parts. In part 1, we developed and validated survey items to understand participant survey taking behavior and motivations for responding dishonestly. In part 2, we developed and validated several simulated scenarios that motivated participants to respond honestly or dishonestly. In part 3, we used these scenarios to assess how frequently participants responded dishonestly and tested whether a short set of items could be used to classify honest and dishonest respondents.

\subsection{Participants}

There were three separate groups of participants. In part 1 of instrument development, there were 45 MTurk workers who helped us develop and validate the self-report survey items (i.e., the survey items about participants' own survey taking behavior). In part 2 of instrument development, there were 37 participants who participated in an in-person pilot survey and cognitive interviews to develop the survey scenarios and discordant respondent indicators (DRI) (i.e., develop a survey flow that ensured participants understood their assigned motivations and paid attention to the instructions). These participants came from a large undergraduate university in California. Finally, there were 141 participants who completed the final version of the survey virtually (part 3). These participants also came from a large undergraduate university in California and were ineligible to participate in part 3 if they had participated in part 2.

Most of the students identified as female (84.40\%) and heterosexual (87.94\%). Students reported performing well in their classes; $92.20 \%$ reported receiving mostly A's and/or B's. Participants were asked to select their race/identity and could select more than one group; this resulted in 16 different combinations. Of these, 27.66\% identified as Latinx, Hispanic, or Chicano, 26.95\% identified as Asian, 26.95\% identified as white, and $18.44 \%$ identified as either Black or African American, Middle Eastern, Native Hawaiian or other Pacific Islander, South Asian, Native American, American Indian, or Alaskan Native, or a combination of the above ${ }^{3}$, When asked how they would describe their income level for most of their life, $32.62 \%$ selected 'middle class', $31.91 \%$ selected 'lower middle class', $23.40 \%$ selected 'upper middle class', $9.93 \%$ selected 'poverty', and $2.13 \%$ selected 'upper class'.

Participants in the main study responded to several validity checks, discussed below, to ensure that they were paying attention to the survey. All participants successfully passed these validity checks and as such no participants were excluded from analysis.

\section{Instrument Development}

\subsection{Item Development (Part 1)}

A central question in any work on invalid responding is: how can we conduct a study about invalid responding and know who is responding invalidly? This question is especially important in discordant responding, where participants may be motivated to be dishonest with researchers if they don't trust their intentions. To address this, we used rigorous qualitative inquiry with two different approaches. The goal of our first approach (part 1) was to learn about the prevalence of and motivations for discordant response behavior by asking participants about their own survey-taking behavior. Clairmont et al. (2018) found that high school and college students reported lying on surveys because they were uncomfortable with the survey topic or method of administration, because they did not trust the researchers or understand the intended uses of the survey,

\footnotetext{
${ }^{3}$ Given that this research is exploratory, we do not have any hypotheses about how participants may respond differently to particular items given their demographics, but it is not unreasonable to expect that demographics may be related to honesty insofar as the survey topic is inherently more sensitive for some groups or institutions have given some groups reason to not to trust them. Future research could address this.
} 
to protect themselves, to protect their family or friends, and to manipulate the survey outcomes. To that extent, we already had qualitative evidence that this behavior occurred, and we developed these items to see if the findings from their small qualitative study would generalize to a larger sample in a survey.

Our goal in this part of the study was twofold, 1) translate the qualitative questions from Clairmont et al. (2018) to survey items that could be assessed quantitatively, 2) assess the degree to which these items replicated findings from Clairmont et al. (2018). Similar reports of dishonest responding in both studies would suggest that we created an environment where participants felt comfortable being honest about their dishonest survey-taking behavior. We made our survey anonymous, as prior work suggests that anonymity promotes honesty (Tourangeau \& Smith, 1996; Tourangeau \& Yan, 2007).

To test the interpretability of our survey items (part 1), we utilized the Response Process Evaluation method (RPE; Wolf et al., 2022, 2023). The RPE method is an iterative mixed method approach to item construction that incorporates feedback from participants to maximize item clarity and comprehension. Rather than respond to each survey item, participants respond to open-ended web probes about each survey item. Participants paraphrase each survey item, give an open-ended response, and then select a corresponding response option. Researchers evaluate each participant's written response to assess item comprehension, and revise and retest new versions of the item (as necessary) until the item and the response options are understood as intended. These survey items were revised and validated with the help of the sample of MTurk workers $(\mathrm{n}=45)$. The fewest number of iterations (revisions) an item went through was one and the most was seven. The final version of each item was evaluated by 20 participants and each was understood correctly $95 \%$ of the time; with a correct interpretation being defined as a shared understanding of the meaning of the item between participants and researchers.

\subsection{Scenario Development (Part 2)}

Part 2 of the instrument development was dedicated to developing simulated scenarios that could be used to detect discordant responses. These scenarios were designed to be about sensitive topics that college students would be able to relate to and either make them feel comfortable responding honestly or feel uncomfortable responding honestly. Instead of responding to these items normally, participants were given the item stem then asked if they would respond honestly or dishonestly. This approach served two purposes: it allowed us to assess the frequency of dishonest responding where participants made their own decisions about their honesty level instead of being instructed to act either honestly or dishonestly, and it addressed potential content-responsive invalid responding by creating a low-stakes environment where participants could admit their dishonesty without providing an answer to the question itsel $f^{4}$ An example of one survey can be seen below in Figures 1 and 2

In addition to lowering the stakes of the assessment to prevent potential faking we also addressed potential content non-responsive behavior due to inattentiveness as we hypothesized that carefully reading each scenario and imagining themselves in a different situation would place a high cognitive burden on participants. To address this, we spent six months conducting 37 rounds of cognitive interviews across 17 different survey versions to develop a layout that reduced potential inattentiveness and excessive cognitive load (Castillo-Díaz \& Padilla, 2013). This process involved inviting students to a lab to complete the pilot surveys under development at that time. Students were told that we wanted feedback on the survey and they would debrief with us after completing the survey to give us this feedback. To build rapport, and encourage thoughtful, honest responses, we dressed casually, spoke colloquially, and encouraged students to pretend they were taking the survey as they normally would at home. We emphasized that this survey was being tested for future use, so there were no wrong answers, and that anything that did not go as expected was something we needed to know so that we could build a better survey. To further discourage socially desirable responses in the lab setting, we told them that they could imagine that they were completing this survey like they normally would at home. We stressed that we wanted feedback from all possible survey takers, so it was okay if they usually took surveys seriously and read every word, and that it was also okay if they usually took surveys half asleep at 3 a.m. the night before a test because they needed extra credit.

\footnotetext{
${ }^{4}$ For example, rather than respond to a survey item such as "Have you ever hazed anyone or been hazed?" with a "yes" or "no", participants told us if they would respond honestly to that survey item. This gave them plausible deniability and made it possible for them to be honest about their dishonesty without revealing their true response to the item. That is, we had no way of knowing if the respondent had hazed someone because we did not collect a response to that item, we simply asked if they would respond honestly, which could happen for reasons other than that they hazed someone.
} 


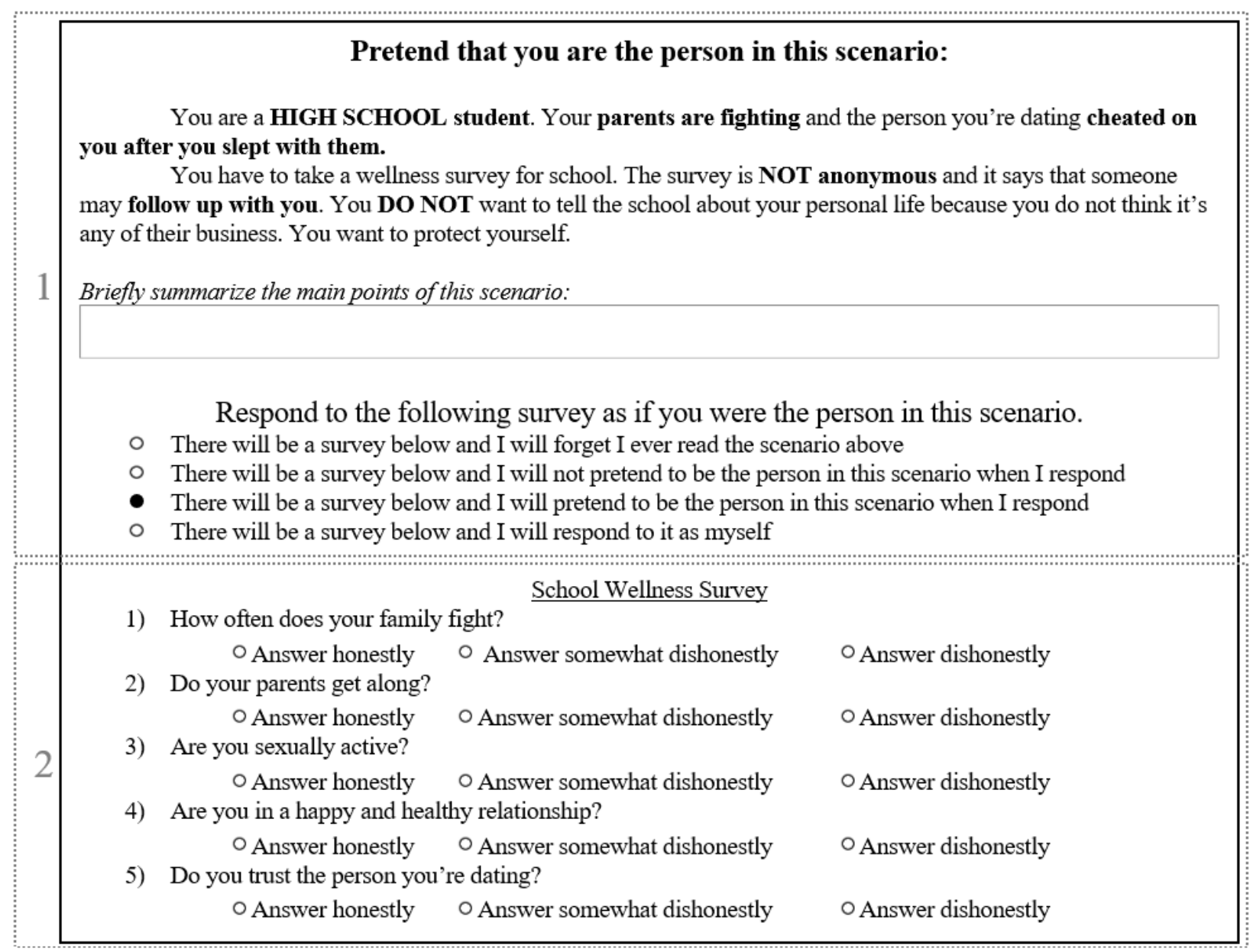

Figure 1: One of the survey scenarios presented to participants. This survey scenario prompted students to feel uncomfortable responding honestly. The survey was presented in two parts: (1) the description of the scenario and (2) the survey questions about the scenario. This was done to compel students to pay attention to the instructions.

After they took the survey, we asked students to think aloud and talk through the responses they selected and asked them if they had noticed various instructions. We also used the cognitive interviews to confirm that participants were being honest about responding honestly or dishonestly. Again, responding dishonestly was low stakes in this context because participants were simply "imagining" how they would act in a certain scenario. Our participants appear to have been sufficiently motivated to respond honestly and provide feedback, as nearly all (91.5\%) selected 'Respond dishonestly' or 'Respond somewhat dishonestly' to at least one survey item even though they knew they would discuss this with us afterwards. This endeavor is a critical element of response process validity, often best informed by qualitative inquiry such as cognitive interviewing (Boness \& Sher, 2020; Castillo-Díaz \& Padilla, 2013).

Our final survey required a significant number of open-ended questions and display logic as participants would often not read instructions unless the instructions were accompanied by a question that they needed to thoughtfully engage with. They would also skip ahead cognitively if they saw other items on the page. To resolve this, we reduced the number of words and sentences in each prompt, displayed each survey scenario prompt by itself, and instructed participants to write a summary of it (this part of the survey can be seen in the first box in Figure 1). Participants were then required to answer a question about the instructions correctly in order to display the next set of items. The ensuing set of items asked participants if they would respond honestly or dishonestly (the second part of the survey can be seen in box two in Figure 1). We added a third response option, 'Respond somewhat dishonestly', because we found that participants would sometimes select 'Respond honestly' and then admit to us in the debriefing that they would have shifted their 


\begin{tabular}{|l|} 
The survey questions continue below. \\
Keep being the character in this scenario.
\end{tabular}

Figure 2: Follow up instructions (3) and the discordant responder identifiers (4) presented after participants responded to each survey scenario. The second half of the survey was also presented in two parts to compel students to pay attention to the instructions.

responses a little but didn't see that as being completely dishonest. Their responses to these items enabled us to classify them as a 'honest' or 'dishonest' responder in each survey scenario.

At the end of each scenario, we also introduced the items to detect discordant responses (discordant responder identifiers; DRI). These items were developed using the findings from the previous qualitative study about the motivations for responding dishonestly on surveys (Clairmont et al., 2018) and can be seen below in Table 1. We developed DRI items that addressed participants' self-reported motivations for responding dishonestly, in the hope that the responses to these items could be used as an indicator of when participants are dishonest. The items addressed a wide range of motivations for dishonesty under the assumption that simply asking dishonest participants if they answered dishonestly would elicit a dishonest response (e.g., we expected that many would say 'Yes' to the Honest DRI item 'Did you respond honestly to this survey?').

Like the previous set of items, the DRI items were presented to the participants only after they answered a multiple-choice question about the instructions (see Figure 2). Participants were told that the DRI items were part of the same survey, and that they should remain in character while responding to them. In total, there were four survey scenarios that each participant responded to; one in which they were motivated to be honest, one in which they were motivated to be dishonest (presented in Figure 1), and two in which they were instructed to respond as themselves on an anonymous and a non-anonymous university-administered survey. The first two scenarios served as validity checks to ensure participants were responding as intended, while the second two scenarios captured more organic participant responses. The four scenarios and accompanying items are included in the Appendix The dataset, $\mathrm{R}$ code, and as a copy of the survey are available on the first author's Open Science Framework page (https://osf.io/whjd6/).

\subsection{Instrument Administration (Part 3)}

In part 3 of the study, we administered the survey to 141 college students. To determine if the DRI items could be used to identify dishonest responses, we classified participants as 'honest' or 'dishonest' depending on how they responded to each of the four survey scenarios. If a participant indicated that they would respond to any items in the survey scenario 'somewhat dishonestly' or 'dishonestly', they were identified as dishonest; if they indicated that they would respond to all item's honesty, they were identified as honest. While there are differences between the participants who said 'somewhat dishonestly' vs 'dishonestly' we 
Table 1: Discordant Responder Identifier (DRI) items.

\begin{tabular}{|c|c|c|c|}
\hline Shorthanc & Item & Response options & Motivation for Inclusion \\
\hline Honest & $\begin{array}{l}\text { Did you respond honestly to } \\
\text { this survey? }\end{array}$ & Yes & This item is commonly used to deter- \\
\hline Comfort & $\begin{array}{l}\text { Did you feel comfortable re- } \\
\text { sponding honestly to this sur- } \\
\text { vey? }\end{array}$ & $\begin{array}{l}\text { Yes, to all } \\
\text { Mostly } \\
\text { Sort of } \\
\text { No, not really }\end{array}$ & $\begin{array}{l}\text { Participants expressed that they would } \\
\text { be less likely to respond honestly if they } \\
\text { were uncomfortable }\end{array}$ \\
\hline Affect & $\begin{array}{l}\text { I think my responses to this sur- } \\
\text { vey will... }\end{array}$ & $\begin{array}{l}\text { Positively affect me } \\
\text { Not affect me } \\
\text { Negatively affect me } \\
\text { Not sure }\end{array}$ & $\begin{array}{l}\text { Participants mentioned worrying about } \\
\text { how the survey results would affect them } \\
\text { if they responded honestly }\end{array}$ \\
\hline Trust & $\begin{array}{l}\text { Do you trust the people who } \\
\text { are giving this survey? }\end{array}$ & $\begin{array}{l}\text { Yes } \\
\text { Mostly } \\
\text { Somewhat } \\
\text { No } \\
\text { Prefer not to say }\end{array}$ & $\begin{array}{l}\text { Participants mentioned that they would } \\
\text { not respond honestly if they did not } \\
\text { trust the survey granting institution }\end{array}$ \\
\hline Use & $\begin{array}{l}\text { Are you comfortable with the } \\
\text { intended uses of this survey? }\end{array}$ & $\begin{array}{l}\text { Yes } \\
\text { Mostly } \\
\text { Somewhat } \\
\text { No } \\
\text { I don't know }\end{array}$ & $\begin{array}{l}\text { Participants were wary to respond hon- } \\
\text { estly to a survey when they disagreed } \\
\text { with its uses }\end{array}$ \\
\hline Other & $\begin{array}{l}\text { How many questions do you } \\
\text { think other people answered } \\
\text { honestly? }\end{array}$ & $\begin{array}{l}\text { All of them } \\
\text { Most of them } \\
\text { Some of them } \\
\text { Hardly any }\end{array}$ & $\begin{array}{l}\text { This item is commonly used to deter- } \\
\text { mine if participants are dishonest }\end{array}$ \\
\hline
\end{tabular}

chose to classify these participants together as both engaged in response distortion, adding measurement error to their responses. We then transposed the data so that there was one outcome variable indicating honest or dishonest response across each of the four scenarios for each participant, and we used the DRI items as predictors of an overall honest or dishonest response. The model is not intended to be explanatory; we are not interested in why a DRI item is good at identifying dishonest responders, only that it is useful in correctly classifying individuals.

After completing each scenario and responding to the DRI items, participants were asked several questions about how frequently they responded dishonestly to surveys and whether certain factors (such as anonymity) influenced how honest they were. One question asked participants to select up to five of the most important aspects that determined whether they responded honestly. Participants could select as few as one or as many as five of these aspects or indicate that they always responded honestly. If a participant selected an aspect, they were then asked how often surveys they typically participated in included this aspect. Finally, participants were asked several demographic questions.

\subsection{DRI Item Analysis}

To determine which items were best at identifying dishonest responses, we used a logistic regression equation with robust standard errors to account for the within person clustering and violation of independence (i.e., the fact that each person responded to all four of the survey scenarios). Robust standard errors were used in lieu of multi-level modeling because modeling random effects was not relevant to the research question and utilizing robust standard errors corrects for the underestimation of standard errors in clustered data (McNeish 
et al., 2016). Bar graphs and non-parametric descriptive statistics were used to summarize participants' motivations for responding dishonestly. All analyses were conducted in $\mathrm{R}$ (version 4.0.3). Robust standard errors were estimated using the 'sandwich' package (Zeileis et al., 2020) and 'Imtest' package (Hothorn et al., 2020). Psuedo R2 statistics were estimated using the 'DescTools' package (Signorell et al., 2021). Plots and descriptive statistics were created using packages in the 'tidyverse' (Wickham \& RStudio, 2019).

\section{Results}

\subsection{Motivations for dishonest responses}

When asked about their own survey taking behavior, $99.29 \%$ of participants said that they considered how the survey results would be used while they were responding to the survey items (see Figure 3). When asked, 'Do you ever choose not to take a survey, stop taking a survey, or skip survey items because you don't like the way your answers will be used?', $21.43 \%$ said 'No, never', $37.86 \%$ said 'Rarely', $25 \%$ said 'Occasionally', $11.43 \%$ said 'Fairly often', and $4.29 \%$ said 'Yes, regularly'. When asked 'Do you ever alter your survey answers to protect yourself because you don't like the way your answers will be used?', $17.02 \%$ said 'No, never', $29.78 \%$ said 'Rarely', 39\% said 'Occasionally', $10.64 \%$ said 'Fairly often', and $3.55 \%$ said 'Yes, regularly'. In summary, almost all participants considered the use of survey results when filling out surveys, and approximately $80 \%$ of participants reported skipping survey items or being dishonest on surveys to protect themselves because they were uncomfortable with uses of the survey.

To find out why students might respond dishonestly (or decline to respond at all), we took the motivations reported in a qualitative study (Clairmont et. al., 2018) and used them to construct response options for the following item: 'What are the most important aspects of a survey that determine if you respond honestly?'. Participants were asked to select up to five of their top criteria for responding honestly and then asked how often they encountered those conditions when they took a survey (see Figure $45^{5}$ The top three responses were 'Anonymity of my responses' (82.27\%), 'Assurance that nothing bad will happen to you' (60.28\%), and 'Trust in the organization giving the survey' (45.39\%). Participants were then asked to rank on a five point scale how often these occurred when they took surveys ('Never', 'Rarely', 'Sometimes', 'Usually', 'Always'). Participants reported that following occurred 'Never' or 'Rarely': 'Anonymity of my responses' $(0 \%)$, 'Assurance that nothing bad will happen to you' (21.17\%), 'Trust in the organization giving the survey' $(6.25 \%)$. In other words, participants reported placing a high value on reassurance that their survey responses wouldn't be used against them but also reported that they often did not receive this assurance 6

\subsection{Identifying dishonest responses}

In total, more than half of time $(51.95 \%)$, participants gave at least one dishonest response while completing a scenario $(7.75 \% \text { in Scenario 1, } 90.85 \% \text { in Scenario 2, 34.51\% in Scenario 3, and } 76.05 \% \text { in Scenario } 4)^{7}$ When asked if they responded honestly, $99.63 \%$ of particpants that responded honestly said that they were honest. However, $63.82 \%$ of participants that actually responded dishonestly lied and said they had answered honestly (see Figure 57. In other words, asking participants if they responded honestly seems to be an excellent predictor of true response when a person truly responded honestly, but not when they responded dishonestly.

There some noticable patterns on the remaining five DRI items. When answering the 'Comfort' DRI item, most of the honest responders $(78.6 \%)$ selected 'Yes, to all', while the dishonest responders were more likely to select 'No, not really' (30.4\%) or 'Mostly' (30.4\%). Conversely, 19.8\% of dishonest responders selected 'Yes, to all', and only $2.6 \%$ of honest responders selected 'No, not really'. Computing odds ratios reveals that honest responders were 14.88 times more likely to select 'Yes, to all' than the dishonest responders, while dishonest responders were 16.45 times more likely to select 'No, not really' (see Figure 4). In other words, participants who responded honestly were much more likely to say they felt comfortable responding honestly, while dishonest responders were much more likely to say that they felt uncomfortable responding honestly (even when they lied and said they responded honestly).

\footnotetext{
${ }^{5}$ Participants could select a maximum of five responses but could select less than five.

${ }^{6}$ Thirteen percent of participants selected the response option "I always answer honestly no matter what". However, these participants also selected other factors that motivated them to respond honestly and admitted that they would answer some of the survey items in the scenarios in the following section dishonestly.

${ }^{7}$ As a reminder, participants were motivated to respond honestly in Scenario 1, dishonestly in Scenario 2, as themselves in an *anonymous* survey in Scenario 3, and as themselves in a *non-anonymous* survey in Scenario 4.
} 


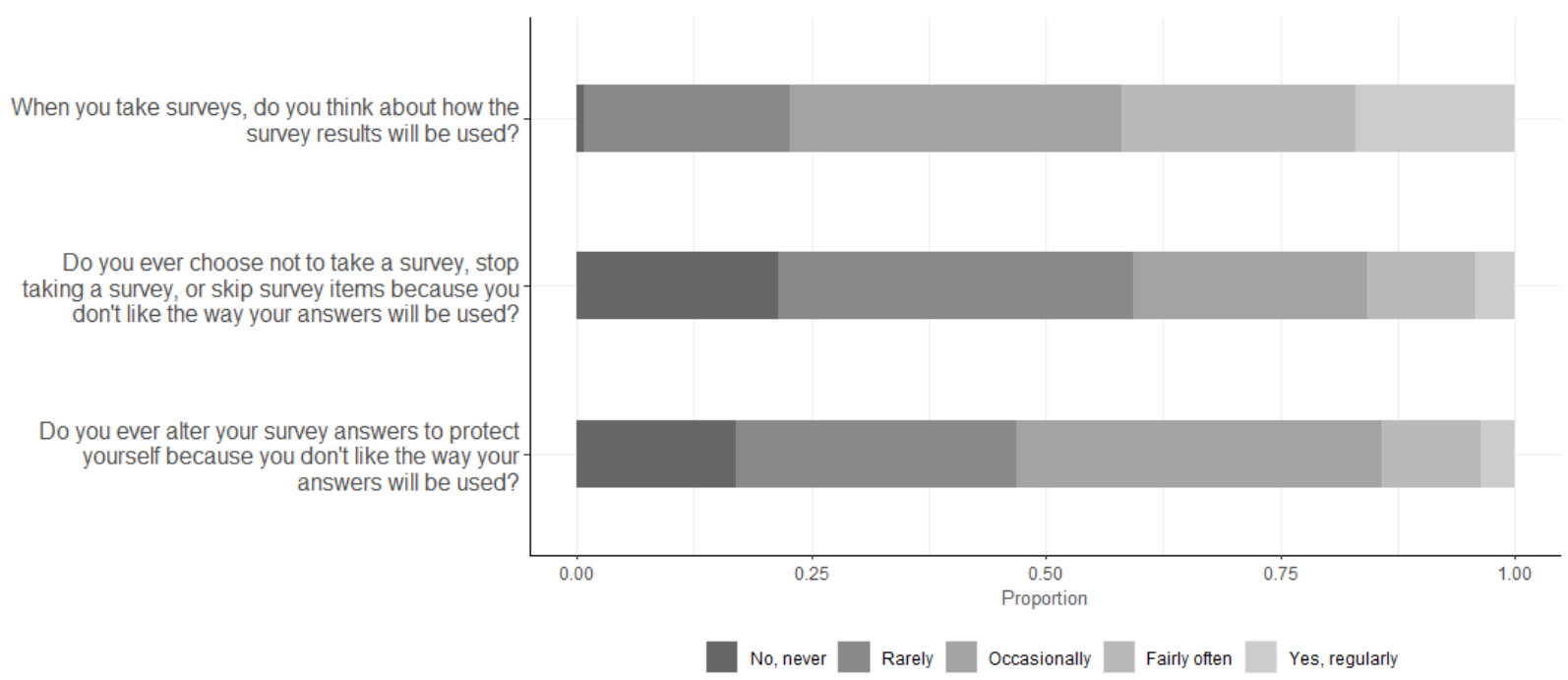

Figure 3: Self-reported consideration of survey use and the subsequent effect on survey responses.

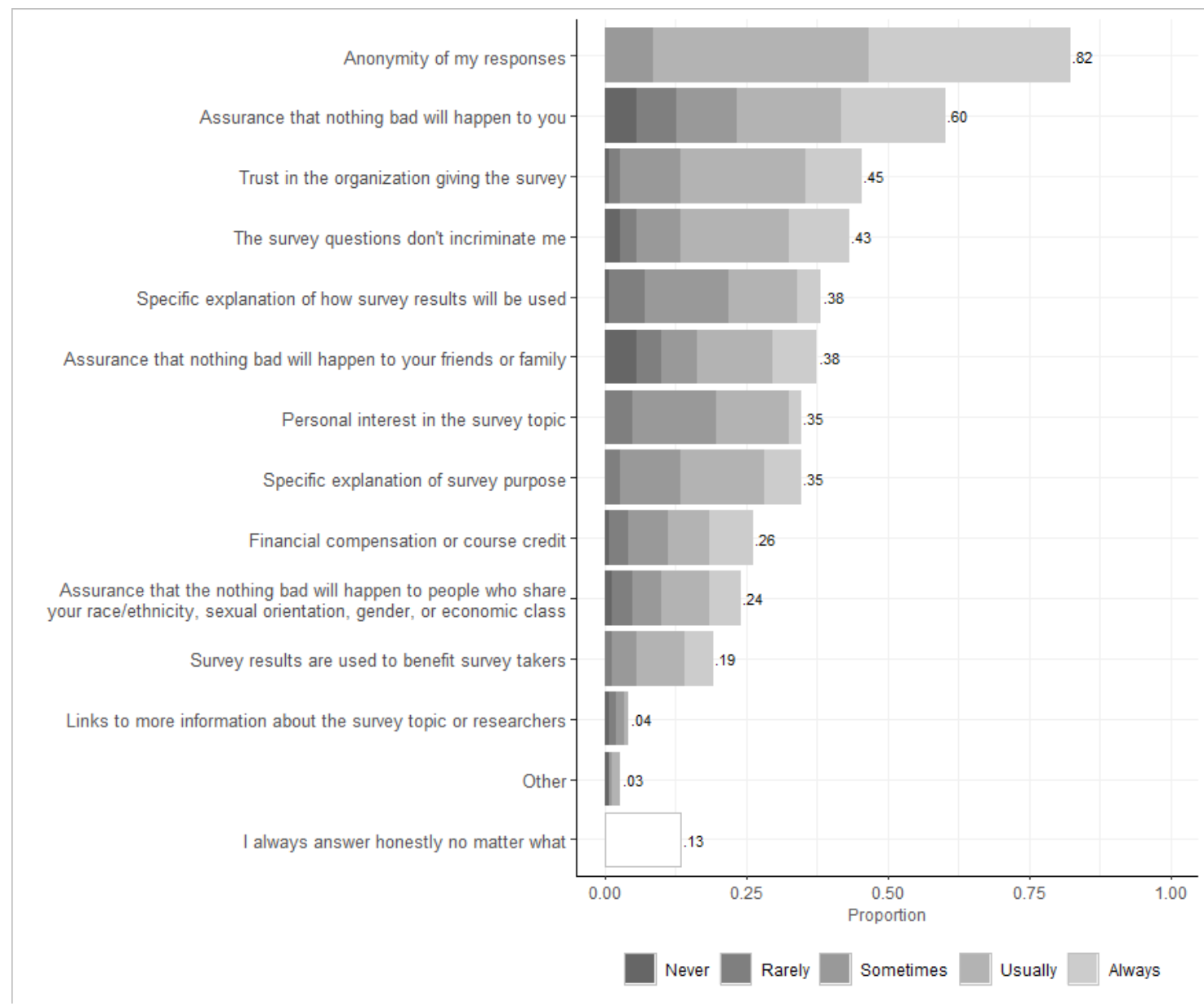

Figure 4: Participant reported top five criteria for responding honestly. The length of the bars represents how the proportion of participants that selected that response option, while the shading of the bars represents how often each occurred in the participant's survey-taking experience. Participants were instructed to select up to five motivations that were most important to them. 
Did you respond honestly to this survey?

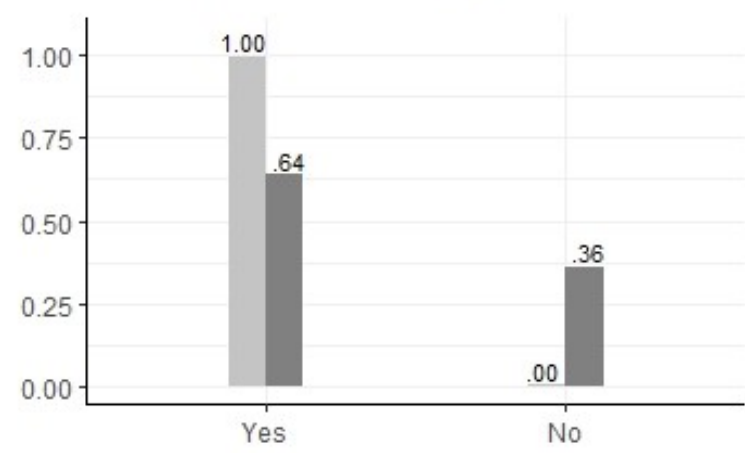

I think my responses to this survey will...

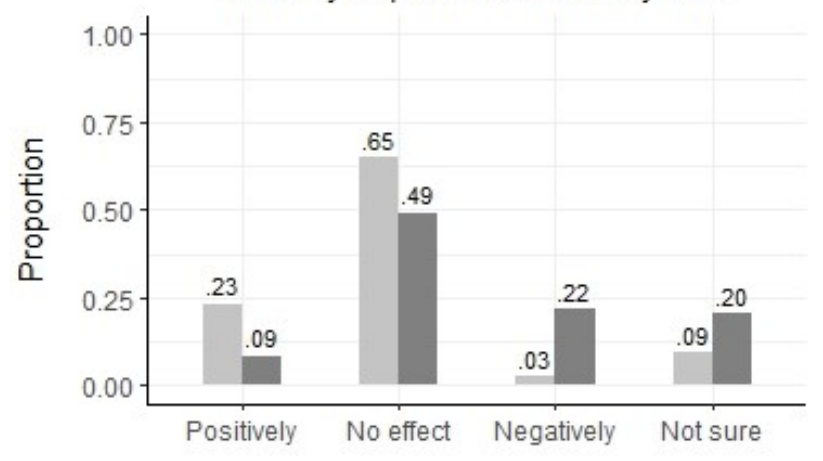

Are you comfortable with the intended uses of this survey?

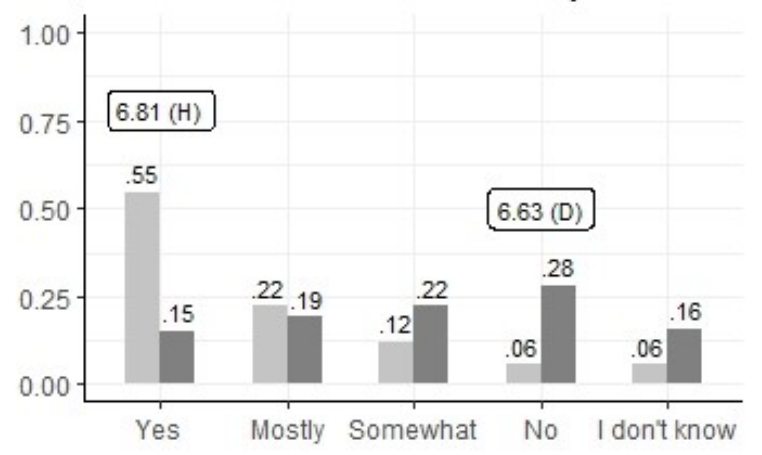

Did you feel comfortable responding honestly to this survey?

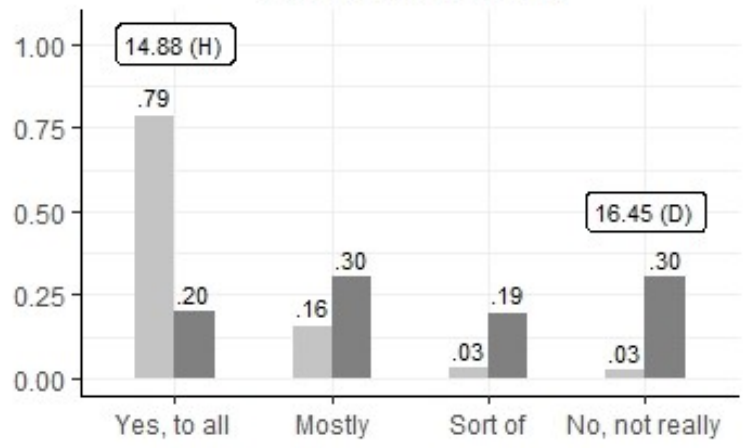

Do you trust the people who are giving this survey?

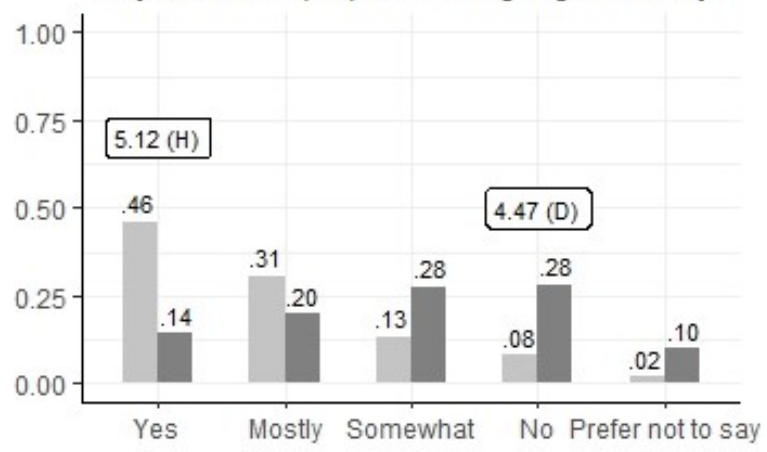

How many questions do you think other people answered honestly?

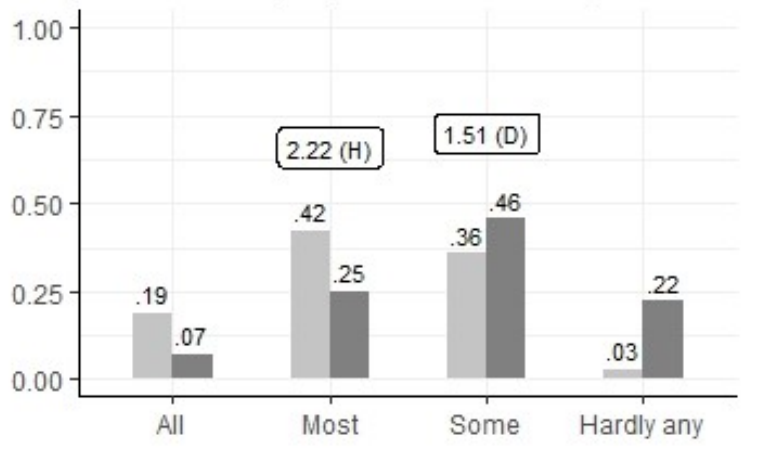

Participant responded honestly

Participant responded dishonestly

Figure 5: Bar plots with the proportion of responders that selected each response option for each discordant response identifier (rowwise, from left to right: Honest, Comfort, Affect, Trust, Use, Other). Odds ratios for the most commonly selected response option for each responder type are also labeled, where $(\mathrm{H})$ stands for "Honest" and (D) stands for "Dishonest". 
The response patterns for the 'Use' and 'Trust' DRI are similar. The most commonly selected response option for honest responders is 'Yes' for both the 'Use' DRI (54.6\%; OR =6.81) and the 'Trust' DRI ( $46.1 \%$; OR = 5.12). The most commonly selected response option for the dishonest responders is 'No' for both the 'Use' DRI $(28 \%$; OR $=6.63)$ and the 'Trust' DRI $(28.3 \%$; OR $=4.47)$. The differences were not as noticable on the 'Affect' and 'Other' DRI's; honest and dishonest responders did not appear to differ in their selection of response options for these items. For the 'Affect' DRI, the most commonly selected response option for both groups was 'No effect'. For the 'Other' DRI, the most commonly selected response option for the honest responders was 'Most of them' $(42.4 \%$; OR $=2.22)$ while the most commonly selected response option for dishonest responders was 'Some of them' $(45.7 \%$; OR $=1.51)$. However, these odds ratios are much smaller. The odds ratio for the 'Honest' DRI is not meaningful since only one honest responder selected 'No' when asked they responded honestly.

Next we ran a logistic regression model with cluster robust standard errors to determine if the DRI's could be used to correctly classify dishonest responders. Since 'dishonest response' was the outcome of interest, we coded 'dishonest response' as 1 and 'honest response' as 0. Given that beta coefficients can be transformed into odds ratios, we expected that the DRI items with the highest odds ratios would be more likely to be useful predictors of dishonest responses. We created two models: a baseline model, to evaluate how well the 'Honest' DRI item alone could correctly classify responses, and a full model with all DRI items The logistic regression results can be seen in Table 2 and the classification proportions can be seen in Table 3

Table 2: Logistic regression results for the baseline and full model.

\begin{tabular}{|c|c|c|c|c|c|}
\hline \multicolumn{6}{|c|}{ Dependent variable: Dishonest Response } \\
\hline & \multirow[b]{2}{*}{ Mostly } & \multicolumn{2}{|c|}{ Baseline } & \multicolumn{2}{|c|}{ Full Model } \\
\hline \multirow{3}{*}{ Comfort } & & & & $1.73^{* * *}$ & $(.28)$ \\
\hline & Sort of & & & $2.51^{* * *}$ & $(.46)$ \\
\hline & No, not really & & & $2.00^{* * *}$ & $(.57)$ \\
\hline Honest & No & $-5.03^{* * *}$ & $(1.01)$ & $3.84^{* * *}$ & $(1.00)$ \\
\hline \multirow{3}{*}{ Affect } & No effect & & & 0.2 & $(.35)$ \\
\hline & Negatively & & & 0.39 & $(.65)$ \\
\hline & Not sure & & & 0.26 & $(.47)$ \\
\hline \multirow{4}{*}{ Trust } & Mostly & & & -0.3 & $(.42)$ \\
\hline & Somewhat & & & -0.01 & $(.47)$ \\
\hline & No & & & -0.62 & $(.70)$ \\
\hline & Prefer not to say & & & $1.36^{+}$ & $(.71)$ \\
\hline \multirow{4}{*}{ Use } & Mostly & & & 0.52 & $(.39)$ \\
\hline & Somewhat & & & $.95^{*}$ & $(.48)$ \\
\hline & No & & & 0.73 & $(.71)$ \\
\hline & I don't know & & & 0.83 & $(.57)$ \\
\hline \multirow{6}{*}{ Other } & Most of them & & & -0.47 & $(.44)$ \\
\hline & Some of them & & & -0.3 & $(.43)$ \\
\hline & Hardly any & & & -0.31 & $(.71)$ \\
\hline & Constant & $4.66^{* * *}$ & $(1.01)$ & $-1.51^{* * *}$ & $(.37)$ \\
\hline & Observations & 564 & & 564 & \\
\hline & Nagelkerke $\mathrm{R}^{2}$ & .31 & & & .55 \\
\hline
\end{tabular}

Note: ${ }^{+p=.05 ; * p<.05 ; * * p<.01 ; * * *} p<0.01$

\footnotetext{
${ }^{8}$ Interaction effects between the scenarios and each of the DRI indicators were not included because the study was not sufficiently powered to detect such effects (e.g., the model already has 18 categories across the 7 predictor variables). Future research could include interaction effects.
} 
A PREPRINT - February 26, 2023

Table 3: Proportion of participants correctly classified in the baseline and full model.

\begin{tabular}{llccccc}
\hline & \multicolumn{2}{c}{ Baseline } & & \multicolumn{2}{c}{ Full Model } \\
& & $\begin{array}{c}\text { Predicted } \\
\text { Honest }\end{array}$ & $\begin{array}{c}\text { Predicted } \\
\text { Dishonest }\end{array}$ & & $\begin{array}{c}\text { Predicted } \\
\text { Honest }\end{array}$ & $\begin{array}{c}\text { Predicted } \\
\text { Dishonest }\end{array}$ \\
\cline { 3 - 4 } \cline { 5 - 6 } Response & $99.63 \%$ & $0.37 \%$ & & $80.81 \%$ & $19.19 \%$ \\
& Honest & $63.82 \%$ & $36.18 \%$ & & $20.14 \%$ & $79.86 \%$ \\
\cline { 3 - 6 } & Dishonest & $63 \%$ &
\end{tabular}

The 'Comfort', 'Honest', and 'Use' DRI's were all statistically significant predictors of dishonest response, indicating that they could be used to help differentiate between honest and dishonest responses (see Table 2). The Nagelkerke R2 was . 31 for the baseline model and .55 for the full model, indicating that the inclusion of the other DRI's meaningfully reduced error in prediction accuracy. This is echoed in Table 3 When only the 'Honest' DRI was included in the model, the model was able to correctly identify $99.63 \%$ of honest responders, but only $36.18 \%$ of dishonest responders. When the full model was used, we were able to correctly classify $80.81 \%$ of honest responders and $79.86 \%$ of dishonest responders. In other words, the inclusion of the other DRI's more than doubled the correct classification of dishonest responses although it did introduce some error into the honest responses.

\section{Discussion}

This study had five aims: (1) to demonstrate that participants consider the use of surveys results when completing them, (2) to gain insight into the prevalence of subsequent discordant responses, (3) to uncover motivations for responding honestly to surveys, (4) to attempt to develop a simple method to detect dishonest responses, and (5) to uncover approaches that may help mitigate discordant responses. Traditionally, researchers have been concerned with invalid response types such as careless or low-effort responses (Curran, 2016), "faking bad" (Robinson-Cimpian, 2014), or "faking good" (Tourangeau \& Yan, 2007).

While research has been concerned with response distortion for protection, this is generally only considered when the items are deemed to be sensitive (Tourangeau \& Yan, 2007). Our study expands upon the protective responding work by introducing a similar but distinct construct that concerns invalid responses that are motivated by disagreement with or mistrust of the survey administrators or use(s) of the survey. This may invoke a nondescript response style: faking "normal". Much like any other form of invalid responding this is a threat to validity because these responses may lead researchers to draw incorrect conclusions from their data.

Our findings show that more than $99 \%$ of participants reported that they have considered the uses of a survey while completing it and over $80 \%$ of participants reported modifying their response process if they did not like the way the survey would be used (Figure 3). While some of the most prominent concerns participants had were about their own safety, concerns about the use of the survey and trust in the survey givers were also prominent concerns (Figure 4). Thus, while sensitive survey content is certainly a primary motivation for responding dishonestly, participants also have other motivations that extend beyond simply protecting themselves. We argue that this supports the view that validity is not solely a property of a survey but of the intended uses and interpretations of the survey results (Kane, 2013; Messick, 1995).

Participants were asked what factors they considered when determining whether to respond honestly and how often these concerns were addressed by researchers. Most (82.27\%) of participants reported that anonymity was one of the most important factors in determining whether to respond honestly. This does not mean that all non-anonymous assessments are biased or that all anonymous assessments are unbiased, however, researchers may want to consider administering anonymous surveys when possible. Participants also noted that it was important for them to trust the organization giving the survey, to clearly understand the uses of the survey, and to be reassured that they would not incriminate themselves and that nothing bad would happen to them (among other things). Importantly, participants also reported that these concerns were often not addressed by the researchers. These findings suggest that it is important for researchers to address these particular topics when creating surveys and research projects to alleviate participant apprehensions. If researchers can assuage these concerns by building trust with their participants, it is possible that discordant responding could be prevented. 


\subsection{Preventing and Detecting Discordant Responses}

An obvious solution to increase trust may be adding additional information to the IRB or instructions section of a survey, however the challenging process of making participants pay attention to information in our study suggests this may be ineffective. In evaluating participants' response processes to ensure they were able to follow the survey prompts, we discovered that students tended to skim instructions and skip ahead to respond to the survey items unless they were required to engage cognitively with the instructions. As such, participants may not closely read excessively lengthy and formal consent forms. This finding also supports past research, which finds that participants generally do not pay attention to consent forms (Baker \& Chartier, 2018; Douglas et al., 2021).

Researchers may want to design consent forms that are easily digestible and utilize display logic or include a pop-up that is accessible throughout the survey if participants have any questions. The content put into the IRB or the survey instructions could be used as an opportunity for researchers to build rapport and trust with participants. If something such as the clarity of an IRB consent form influences a participant's survey responses, then evidence of validity for the IRB consent form could be warranted. Creating conscientious assessments with the participant's perspective in mind could reduce discordant responding and improve data quality.

Finally, we also developed the DRI items to help researchers identify dishonest responses in their own studies. In this study, participants were dishonest on surveys more often than they were honest (51.95\% of responses were dishonest). Of the participants that were dishonest, when asked if they were dishonest, $36.17 \%$ admitted responding dishonestly while $63.82 \%$ lied and said they responded honestly. If we were to simply ask participants if they were dishonest and trust their responses, we would have misclassified more than half of the dishonest responses. The inclusion of DRI items enabled us to identify twice as many dishonest responses $(79.86 \%)$; with the best performing items being: 'Did you feel comfortable responding honestly to this survey?' and 'Are you comfortable with the intended uses of this survey?'. Notedly, these DRI items speak to participant motivation and their relationship with the researcher rather than participant behavior. Most participants who responded dishonestly to the surveys could be identified by their responses to these two items.

While including the DRI items increased dishonest response detection rate, these additional DRI items did cause us to misclassify $20.13 \%$ of honest responses as dishonest. Because of this, we caution researchers against using these items simply to remove respondents for being dishonest. Instead, we propose the use of these items during survey development or pilot testing as a way to determine if respondents are uncomfortable with the survey. The researchers could then engage in qualitative follow-up with participants to determine what aspects of the survey are uncomfortable or concerning and modify these features before the full study is run. This process could also help to make the $20 \%$ of respondents who responded honestly, but still had some level of discomfort with the survey itself, feel more comfortable.

Notedly, the DRI items that we developed are a small subset of all possible DRI items (and response option formats for the selected DRI items) that could be used to detect discordant or dishonest responses. As such, we do not present the DRI as a finalized scale, but a demonstration that it is possible to use items to identify discordant responses on assessments. This kind of scale is warranted because some of the most popular alternatives (e.g., the MMPI) are lengthy and proprietary, and thus may not be appropriate for all areas of research. In the case of the DRI items developed here, if a participant selected 'Yes' when asked if they responded honestly but also selected 'No' when asked if they felt comfortable responding honestly and 'No' when asked if they were comfortable with the intended uses of the survey, there is a higher likelihood that they were dishonest. Thus, while students may be dishonest about their honesty, they tended to be more honest about how uncomfortable they were. Further, although the 'Trust' DRI was non-significant, it had a large odds ratio and 'Trust in the organization giving the survey' was the third most important reported motivation for responding honestly (e.g., students who selected 'Prefer not to say' when asked if they trusted the people administering the survey were more likely to be dishonest). DRI items about comfort, use, and trust could be a promising avenue for identifying deception. In particular, a "prefer not to respond" option could be illuminating as it flags insecurity for researchers but promotes the same sort of plausible deniability used in the scenarios for participants (e.g., participants do not need to openly admit that they question the trustworthiness of the people administering the survey).

Deciding what to do about discordant responses is difficult because often the discordant responses may be the most interesting cases (e.g., persons with the most sensitive responses to sensitive questions have more motivation to respond dishonestly, and they would be difficult to identify from quantitative analyses alone because their surveys responses would intentionally mimic a "normative" response pattern). While we suggest 
above that the DRI items be used in the pilot-phase of survey development to diagnose and address problems with dishonest responding, we acknowledge that this is not always possible. Thus, we also suggest that DRI's could be used as a form of survey weighting. A numeric value could be associated with each DRI and a total score for each participant could be computed (where a high score suggests dishonesty). Depending on the intended uses of the survey, researchers could either down weight responses proportional to that score, remove cases with excessively high scores, or in the case of non-anonymous screener surveys, they could follow up with theses participants.

There is not necessarily a 'one-size-fits-all' approach to deal with dishonest responses. With large scale anonymous surveys that do not intend to make person level inferences, dishonest responses may be less of a threat or concern. Conversely, with non-anonymous assessments about sensitive topics, such mental health screeners in high school, a Type I error (mistakenly classifying honest responders as dishonest) may be more permissible to improve the power of their study (the ability to identify participants that need help). However, we again encourage researchers to utilize qualitative inquiry to understand the process that is generating this dishonest data, as simply assuming what the underlying process is and attempting to correct for it could further bias conclusions from a study.

As has been the common theme throughout this article, we encourage researchers to use conscientious survey design to address these problems. The best solution to the problem of dishonest responding is to understand why participants are responding dishonestly to begin with and resolve that problem a priori instead of attempting to make corrections for this behavior ad-hoc. We hope the tools we have provided in this article in terms of the DRI items and qualitative methods will help researchers design surveys that will encourage all participants to respond honestly and conscientiously.

\subsection{Limitations}

As with any study, it is possible that the framing of items or the order of items may bias participants' responses (Schwarz, 1999). Despite the extensive qualitative research that went into constructing this survey, it is possible that some students may have lied to protect themselves. Alternatively, the content of the study could have primed participants to report a higher level of dishonest responding due to the sensitive nature of many of the questions. None of the survey scenarios clearly explained the intended use of the data, which may have caused participants to feel more uncomfortable responding honestly (although, this was intentional and a central thesis of the study). However, the fact that $91.5 \%$ of students selected a dishonest response in at least one survey scenario reassures us that most students were being honest about their dishonesty (although their own self-reported dishonest behavior could have been exaggerated). These limitations are no different from the ones that all other studies face; they are simply highlighted given the topic of the paper.

Additionally, there were several ways that participants could have been classified as honest or dishonest. We chose to classify all participants that answered at least one question "somewhat dishonestly" as dishonest in that particular scenario. However, researchers and psychologists could have different thresholds for dishonesty tolerance. It could be argued that one "little white lie" should be permissible and that these participants should be classified as honest. However, where does one draw the line? This is a common issue in psychology with classification and cut scores (Steegen et al., 2016).

If we had reclassified the "one little white lie" respondents as "honest" and created a higher threshold for dishonesty (i.e., at least two dishonest responses across five items), this would have reclassified $7.45 \%$ of the respondents across all scenarios as honest (one participant from Scenario 1, four participants from 2, 19 participants from Scenario 3, and 18 participants from Scenario 4). It would have reduced the percent of participants that responded dishonestly from just over half $(51.95 \%)$ to under half $(44.50 \%)$. However, it would not have changed the logistic regression results meaningfully (e.g., the Nagelkerke R2 would have increased by .002, the "Comfort" and "Use" DRI's would have remained significant, and the "Trust" DRI would have crossed the over into the significance territory; from $\mathrm{p}=.05$ to $\mathrm{p}=.002$ ). As such, the results are fairly stable across the two most reasonable ways to classify participants as honest or dishonest. We hope by providing the data and code for these analyses to researchers it allows them to investigate issues such as specific cut scores they feel comfortable with in their own research.

We were also unable to assess convergent validity of the DRI items with popular alternatives, such as the MMPI. Future research should investigate the convergent validity of these two scales to assess the degree to which the DRI can be used as a standalone alternative to the MMPI for detecting dishonest responding. We expect that it is unlikely that DRI items are a perfect replacement for detecting dishonest respondents in a high stakes clinical setting but expect that it will have similar efficacy in lower stakes or research settings. Importantly, responses to DRI items can also be used a priori during pretesting to help researchers identify 
if they have an instrument or environment in which participants are distrustful or unmotivated to respond honestly, and subsequently make modifications to prevent dishonest responses. DRI's may also be more appropriate on shorter screener scales, or other situations in which lengthy, proprietary scales such as the MMPI are not a feasible addition.

Finally, our study is only a preliminary investigation of discordant responding. We recognize that there are many questions unanswered in this area because they were outside the scope of our study. The goal of our paper is not to provide a definitive exploration of discordant responding or of methods to detect/deter this behavior, but instead serves as a call to the field for greater consideration of how response processes such as these may bias the validity of our work. This work also highlights the importance of building trust between researchers and participants and developing psychological studies with the participant's perspective in mind. We hope that providing our data, materials, and code aids future research in this area and acts as a springboard for researchers who are interested in pursuing such work.

\section{References}

AERA, APA, NCME. (2014). Validity. In Standards for Educational and Psychological Testing (pp. 11-31). American Educational Research Association.

Baer, R. A., Ballenger, J., Berry, D. T. R., \& Wetter, M. W. (1997). Detection of random responding on the MMPI-A. Journal of Personality Assessment, 68(1), 139-151. https://doi.org/10.1207/ s15327752jpa6801_11

Bagby, R. M., \& Sellbom, M. (2018). The Validity and Clinical Utility of the Personality Inventory for DSM-5 Response Inconsistency Scale. Journal of Personality Assessment, 100(4), 398-405. https: //doi.org/10.1080/00223891.2017.1420659

Baker, D., \& Chartier, C. R. (2018). Participant Attentiveness to Consent Forms. Psi Chi Journal of Psychological Research, 23(2), 142-146. https://doi.org/10/gdm9mf

Ben-Porath, Y. F. (2011). Interpreting the MMPI-2-RF. University of Minnesota Press. https://www. upress.umn.edu/book-division/books/interpreting-the-mmpi-2-rf

Berry, D. T. R., Wetter, M. W., Baer, R. A., Larsen, L., Clark, C., \& Monroe, K. (1992). MMPI-2 random responding indices: Validation using a self-report methodology. Psychological Assessment, 4(3), 340-345. https://doi.org/10.1037/1040-3590.4.3.340

Berry, K., Rana, R., Lockwood, A., Fletcher, L., \& Pratt, D. (2019). Factors associated with inattentive responding in online survey research. Personality and Individual Differences, 149, 157-159. https://doi. org/10/gmhzmb

Boness, C. L., \& Sher, K. J. (2020). The Case for Cognitive Interviewing in Survey Item Validation: A Useful Approach for Improving the Measurement and Assessment of Substance Use Disorders. Journal of Studies on Alcohol and Drugs, 81(4), 401-404.

Borsboom, D., Mellenbergh, G. J., \& van Heerden, J. (2004). The Concept of Validity. Psychological Review, 111(4), 1061-1071. https://doi.org/10.1037/0033-295X.111.4.1061

Bowling, N. A., Gibson, A. M., Houpt, J. W., \& Brower, C. K. (2020). Will the Questions Ever End? Person-Level Increases in Careless Responding During Questionnaire Completion. Organizational Research Methods, 1094428120947794. https://doi.org/10/gg9cvg

Bowling, N. A., Huang, J. L., Bragg, C. B., Khazon, S., Liu, M., \& Blackmore, C. E. (2016). Who cares and who is careless? Insufficient effort responding as a reflection of respondent personality. Journal of Personality and Social Psychology, 111(2), 218-229. https://doi.org/10/gddpcv

Brower, C. K. (2018). Too Long and Too Boring: The Effects of Survey Length and Interest on Careless Responding [Thesis]. Wright State University.

Cao, M., \& Drasgow, F. (2019). Does forcing reduce faking? A meta-analytic review of forced-choice personality measures in high-stakes situations. Journal of Applied Psychology, 104(11), 1347-1368. https: //doi.org/10.1037/ap10000414 
Castillo-Díaz, M., \& Padilla, J. L. (2013). How Cognitive Interviewing can Provide Validity Evidence of the Response Processes to Scale Items. Social Indicators Research, 114(3), 963-975. https://doi.org/10. 1007/s11205-012-0184-8

Cimpian, J. R., \& Timmer, J. D. (2019). Large-Scale Estimates of LGBQ-Heterosexual Disparities in the Presence of Potentially Mischievous Responders: A Preregistered Replication and Comparison of Methods. AERA Open, 5(4), 2332858419888892. https://doi.org/10.1177/2332858419888892

Cimpian, J. R., Timmer, J. D., Birkett, M. A., Marro, R. L., Turner, B. C., \& Phillips, G. L. (2018). Bias From Potentially Mischievous Responders on Large-Scale Estimates of Lesbian, Gay, Bisexual, or Questioning (LGBQ)-Heterosexual Youth Health Disparities. American Journal of Public Health, 108(S4), S258-S265. https://doi.org/10.2105/AJPH.2018.304407

Clairmont, A., Wolf, M. G., \& Maul, A. (2018). A Taxonomy of Invalid Responders: Understanding a Threat to Validity. American Educational Research Association.

Crowne, D. P., \& Marlowe, D. (1960). A new scale of social desirability independent of psychopathology. Journal of Consulting Psychology, 24(4), 349-354. https://doi.org/10.1037/h0047358

Curran, P. G. (2016). Methods for the detection of carelessly invalid responses in survey data. Journal of Experimental Social Psychology, 66, 4-19. https://doi.org/10.1016/j.jesp.2015.07.006

Curran, P. G., \& Hauser, K. A. (2019). I'm paid biweekly, just not by leprechauns: Evaluating validbut-incorrect response rates to attention check items. Journal of Research in Personality, 82, 103849. https://doi.org/10.1016/j.jrp.2019.103849

Douglas, B. D., McGorray, E. L., \& Ewell, P. J. (2021). Some researchers wear yellow pants, but even fewer participants read consent forms: Exploring and improving consent form reading in human subjects research. Psychological Methods, 26(1), 61-68. https://doi.org/10/fdsn

Fish, J. N., \& Russell, S. T. (2018). Have Mischievous Responders Misidentified Sexual Minority Youth Disparities in the National Longitudinal Study of Adolescent to Adult Health? Archives of Sexual Behavior, 47(4), 1053-1067. https://doi.org/10.1007/s10508-017-0993-6

Fowler, F. J. (1995). Improving survey questions: Design and evaluation (pp. viii, 191). Sage Publications, Inc.

Graham, J. R. (2006). MMPI-2: Assessing personality and psychopathology (4th ed.). Oxford University Press.

Grow, R., McVaugr, W., \& Eno, T. D. (1980). Faking and the Mmpi. Journal of Clinical Psychology, 36(4), 910-917. https://doi.org/10.1002/1097-4679(198010)36:4<910::AID-JCLP2270360412>3.0.CO;2-X

Hothorn, T., Zeileis, A., Farebrother (pan.f), R. W., Cummins (pan.f), C., Millo, G., \& Mitchell, D. (2020). lmtest: Testing Linear Regression Models (0.9-38). https://CRAN.R-project.org/package=lmtest

Johnson, J. A. (2005). Ascertaining the validity of individual protocols from web-based personality inventories. Journal of Research in Personality, 39(1), 103-129. https://doi.org/10.1016/j.jrp. 2004.09.009

Kane, M. T. (2013). Validation as a Pragmatic, Scientific Activity: Validation as a Pragmatic, Scientific Activity. Journal of Educational Measurement, 50(1), 115-122. https://doi.org/10.1111/jedm.12007

Krohn, M. D., Lizotte, A. J., Phillips, M. D., Thornberry, T. P., \& Bell, K. A. (2013). Explaining Systematic Bias in Self-Reported Measures: Factors that Affect the Under- and Over-Reporting of Self-Reported Arrests. Justice Quarterly, 30(3), 501-528. https://doi.org/10.1080/07418825.2011.606226

Krumpal, I. (2013). Determinants of social desirability bias in sensitive surveys: A literature review. Quality and Quantity, 47(4), 2025-2047. https://doi.org/10.1007/s11135-011-9640-9

Kung, F. Y. H., Kwok, N., \& Brown, D. J. (2018). Are Attention Check Questions a Threat to Scale Validity? Applied Psychology, 67(2), 264-283. https://doi.org/10.1111/apps.12108

Maniaci, M. R., \& Rogge, R. D. (2014). Caring about carelessness: Participant inattention and its effects on research. Journal of Research in Personality, 48, 61-83. https://doi.org/10.1016/j.jrp.2013.09.008

McGrath, R. E., Mitchell, M., Kim, B. H., \& Hough, L. (2010). Evidence for response bias as a source of error variance in applied assessment. Psychological Bulletin, 136(3), 450-470. https://doi.org/10.1037/ a0019216 
McNeish, D., Stapleton, L., \& Silverman, R. D. (2016). On the unnecessary ubiquity of hierarchical linear modeling. Psychological Methods, 22(1), 114-140.

Meade, A. W., \& Craig, S. B. (2012). Identifying careless responses in survey data. Psychological Methods, 17(3), 437-455. https://doi.org/10.1037/a0028085

Meehl, P. E., \& Hathaway, S. R. (1946). The K factor as a suppressor variable in the Minnesota Multiphasic Personality Inventory. Journal of Applied Psychology, 30(5), 525-564. https://doi.org/10.1037/h0053634

Messick, S. (1995). Validity of Psychological Assessment: Validation of Inferences from Persons' Responses and Performances as Scientific Inquiry into Score Meaning. American Psychologist, 50(9), 741-749.

Nederhof, A. J. (1985). Methods of coping with social desirability bias: A review. European Journal of Social Psychology, 15(3), 263-280. https://doi.org/10.1002/ejsp.2420150303

Nichols, A. L., \& Edlund, J. E. (2020). Why don't we care more about carelessness? Understanding the causes and consequences of careless participants. International Journal of Social Research Methodology, 23(6), 625-638. https://doi.org/10/gg44c5

Nichols, D., Greene, R., \& Schmolck, P. (1989). Criteria for assessing inconsistent patterns of item endorsement on the MMPI: Rationale, development, and empirical trials. Journal of Clinical Psychology, 45(2), 12. https://doi.org/10.1002/1097-4679(198903)45:2<239::AID-JCLP2270450210>3.0.CO;2-1

Robinson-Cimpian, J. P. (2014). Inaccurate Estimation of Disparities Due to Mischievous Responders: Several Suggestions to Assess Conclusions. Educational Researcher, 43(4), 171-185.

Rogers, R., Sewell, K. W., Martin, M. A., \& Vitacco, M. J. (2003). Detection of Feigned Mental Disorders: A Meta-Analysis of the MMPI-2 and Malingering. Assessment, 10(2), 160-177. https://doi.org/10.1177/ 1073191103010002007

Rosenfeld, B., Imai, K., \& Shapiro, J. N. (2016). An Empirical Validation Study of Popular Survey Methodologies for Sensitive Questions: VALIDATION OF SURVEY METHODOLOGIES FOR SENSITIVE QUESTIONS. American Journal of Political Science, 60(3), 783-802. https://doi.org/10.1111/ajps. 12205

Ross, R. M., \& Levy, N. (2023). Expressive Responding in Support of Donald Trump: An Extended Replication of Schaffner and Luks (2018). Collabra: Psychology, 9(1), 68054. https://doi.org/10.1525/ collabra.68054

Schwarz, N. (1999). Self-reports: How the questions shape the answers. American Psychologist, 54(2), 93-105. https://doi.org/10.1037/0003-066X.54.2.93

Signorell, A., Aho, K., Alfons, A., Anderegg, N., Aragon, T., Arachchige, C., Arppe, A., Baddeley, A., Barton, K., Bolker, B., Borchers, H. W., Caeiro, F., Champely, S., Chessel, D., Chhay, L., Cooper, N., Cummins, C., Dewey, M., Doran, H. C., ... Zeileis, A. (2021). DescTools: Tools for Descriptive Statistics (0.99.40). https://CRAN.R-project.org/package=DescTools

Splett, J. W., Fowler, J., Weist, M. D., McDaniel, H., \& Dvorsky, M. (2013). The Critical Role of School Psychology in the School Mental Health Movement. Psychology in the Schools, 50(3), 245-258. https://doi.org/10.1002/pits.21677

Steegen, S., Tuerlinckx, F., Gelman, A., \& Vanpaemel, W. (2016). Increasing Transparency Through a Multiverse Analysis. Perspectives on Psychological Science, 11(5), 702-712. https://doi.org/10.1177/ 1745691616658637

Stöber, J. (2001). The Social Desirability Scale-17 (SDS-17). European Journal of Psychological Assessment, 17(3), 222-232. https://doi.org/10.1027//1015-5759.17.3.222

Tourangeau, R., \& Smith, T. W. (1996). Asking Sensitive Questions: The Impact of Data Collection Mode, Question Format, and Question Context. Public Opinion Quarterly, 60(2), 275. https://doi.org/10.1086/ 297751

Tourangeau, R., \& Yan, T. (2007). Sensitive questions in surveys. Psychological Bulletin, 133(5), 859-883. https://doi.org/10.1037/0033-2909.133.5.859

Wickham, H., \& RStudio. (2019). tidyverse: Easily Install and Load the "Tidyverse" (1.3.0). https: //CRAN.R-project.org/package=tidyverse 
Wolf, M. G., Ihm, E., Maul, A., \& Taves, A. (2022). Survey Item Validation. In S. Engler \& M. Stausberg (Eds.), Handbook of Research Methods in the Study of Religion (2nd ed., pp. 612-624). Routledge.

Wolf, M. G., Taves, A., Ihm, E., \& Maul, A. (2023). The Response Process Evaluation Method. PsyArXiv. https://doi.org/10.31234/osf.io/rbd2x

Zeileis, A., Lumley, T., Graham, N., \& Koell, S. (2020). sandwich: Robust Covariance Matrix Estimators (3.0-0). https://CRAN.R-project.org/package=sandwich

\section{Appendix}

\section{Survey Scenario 1: Motivated to be honest.}

Scenario

You are a college student at a large university who has never used opioids (oxycontin, heroin, etc.). None of your close friends or family use opioids either. Your school announced that they will offer free rehab services for students with opioid addictions. You think this is a good initiative, but it doesn't affect you. The school sends out an anonymous online survey to learn about opioid use so that they can plan their rehab program.

\section{Survey Items}

1. Have you ever had a sexually transmitted infection?

2. Have you ever sent nude photos of yourself?

3. Have you ever peer pressured someone into drinking or doing drugs?

4. Have you ever hazed anyone or been hazed?

5. Do you call an ambulance if your friend is too drunk?

\section{Survey Scenario 2: Motivated to be dishonest.}

\section{Scenario}

You are a high school student. Your parents are fighting and the person you're dating cheated on you after you slept with them. You have to take a wellness survey for school. The survey is not anonymous, and it says that someone may follow up with you. You do not want to tell the school about your personal life because you do not think it's any of their business. You want to protect yourself.

Survey Items

1. How often does your family fight?

2. Do your parents get along?

3. Are you sexually active?

4. Are you in a happy and healthy relationship?

5. Do you trust the person you're dating?

\section{Survey Scenario 3: No motivation; anonymous survey.}

Scenario

As a college student, you are regularly asked to take surveys. Imagine that you are asked to complete the following anonymous survey.

Survey Items

1. Have you ever had a sexually transmitted infection?

2. Have you ever sent nude photos of yourself?

3. Have you ever peer pressured someone into drinking or doing drugs? 
4. Have you ever hazed anyone or been hazed?

5. Do you call an ambulance if your friend is too drunk?

\section{Survey Scenario 4: No motivation, non-anonymous survey.}

Scenario

When you are asked to complete surveys at college, your answers are normally anonymous. Imagine that you are asked to complete a survey that is not anonymous and are told that someone may follow up with you based on your responses. You enter your name and student ID and begin answering survey items.

Survey Items

1. Have you ever used illegal drugs?

2. How often do you watch porn?

3. How many sexual partners have you had?

4. Have you ever bullied anyone?

5. Have you ever cheated or plagiarized anything? 